\title{
Violence and lie in Vietnamese folktales: some opinions
}

\author{
Quang-Loc Nguyen \\ Ritsumeikan Asia Pacific University \\ Jumonjibaru, Beppu, Oita, 874-8577 Japan \\ February 23, 2021
}

Lie and violence transmitted by religions are sensitive topics that catch great attention worldwide $[1,2]$. "On how religions could accidentally incite lies and violence: Folktales as a cultural transmitter" is a study that comprehensively analyses culture, traditional values and social contexts in Vietnam [3]. This paper attempts to review its historical shortage, social limitation, and contribution to interpreting Vietnamese society's complexity.

Vuong et al. could not capitalize on some of their most interesting findings, such as why folklorists give the message of lie and violence in the stories. Tracing back to Vietnam history, which is popular for fighting against colonizers, helps to explain the context. For example, Mrs. Dau (Chi Dau) in Ngo Tat To' Tat Den story fights against the officers to protect her family may interpret to the negative to Confucian values (disloyalty to the king), but, the positive outcome (maintaining her survival and her family's lives). This case may make us re-consider whether Mrs. Dau should follow Confucian values or her survival purpose.

In some cases, the followers may not consider violence and lie as deviant behaviors [4]. For example, violence is not always viewed as positive and negative regarding social justice but exchangeable [5,6]. In terms of lying, Confucianism values the interpersonal relationship - guanxi - that encourages people to avoid losing other's images [7]. They may carefully speak to others, even lie, in order to avoid direct criticism towards others. Therefore, the positive and negative terms used in the paper should be applied only to Vietnamese folktales to avoid confusions from another social context.

Yet, for all these problems, Vuong et al.'s paper is brimming with energy and ingenuity. They have assembled some nice data, for example, the characters' behaviors in several hundred Vietnamese folklores, the comparative importance of Three Teachings, and social contexts. They have proposed intriguing and often compelling interpretations of religious messages, cultural values and social norms, especially in the context with high cultural additivity level like Vietnam [8].

To sum up, On how religions could accidentally incite lies and violence: Folktales as a cultural transmitter is a should-read paper to those interested in studying social phenomena. This essay has tried to review the shortage, limitation and noticeable points of the paper.

\section{Reference}

[1] Professor of Sociology and Anthropology David G. Bromley, David G. Bromley, and J. Gordon Melton. (2002). Cults, Religion, and Violence. Cambridge University Press.

[2] Religion and Violence. (1987). Westminster John Knox Press.

[3] Quan-Hoang Vuong, et al. (2020). On how religions could accidentally incite lies and violence: folktales as a cultural transmitter. Palgrave Communications, 6(1), 82.

[4] Lisa Hajjar. (2004). Religion, state power, and domestic violence in Muslim societies: A framework for comparative analysis. Law \& Social Inquiry, 29(1), 1-38. 
[5] J. Galtung. (1969). Violence, peace, and peace research. Journal of peace research, 6(3), $167-191$.

[6] Stanley Jeyaraja Tambiah. (1992). Buddhism Betrayed?: Religion, Politics, and Violence in Sri Lanka. University of Chicago Press.

[7] Zhongqi Pan. (2016). Guanxi, Weiqi and Chinese strategic thinking. Chinese Political Science Review, (1)2, 303-321.

[8] Quan-Hoang Vuong, et al. (2018). Cultural additivity: behavioural insights from the interaction of Confucianism, Buddhism and Taoism in folktales. Palgrave Communications, $4(1), 143$ 